\title{
Recanalization of postoperative biliary disconnection with intraductal cholangioscopy-assisted forceps retrieval of rendezvous guidewire
}

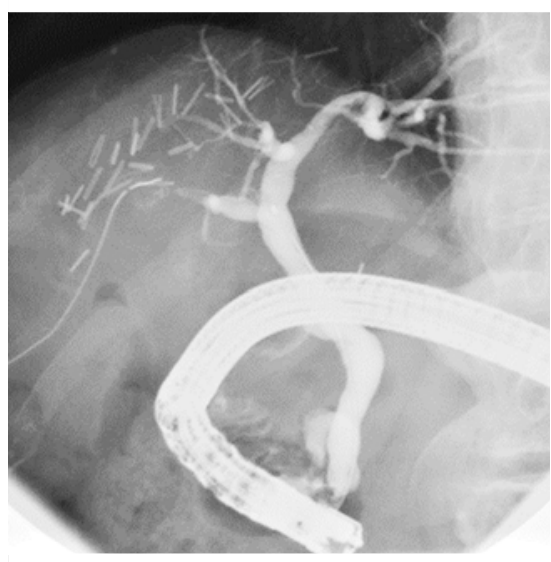

- Fig. 1 Endoscopic retrograde cholangiography showing complete bile duct obstruction after laparoscopic right anterior hepatectomy with no flow of contrast into the right posterior branch.

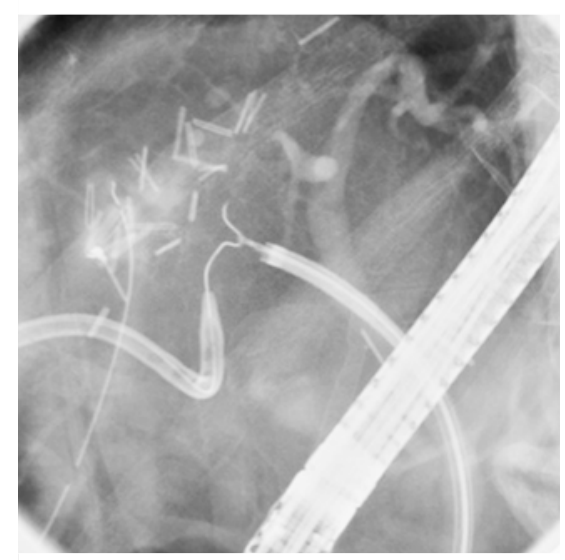

- Fig. 4 Fluoroscopic imaging showing the guidewire grasped by forceps under intraductal cholangioscopy guidance.

Biliary recanalization is a vital procedure to restore postoperative bile duct obstruction. However, selective guidewire negotiation across the disconnected sites under fluorescence imaging is challenging. We present a case of formidable biliary disconnection after hepatectomy that was recanalized by rendezvous technique using digital cholangioscopy.

An 86-year-old man with hepatocellular carcinoma in the right anterior segment showed bile leakage at the resection site

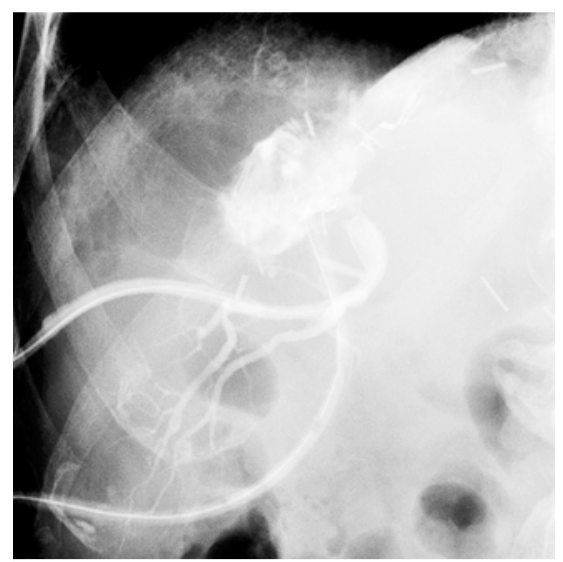

- Fig. 2 Percutaneous transhepatic cholangiography showing bile leakage into the peritoneal cavity with no flow of contrast into the common bile duct.

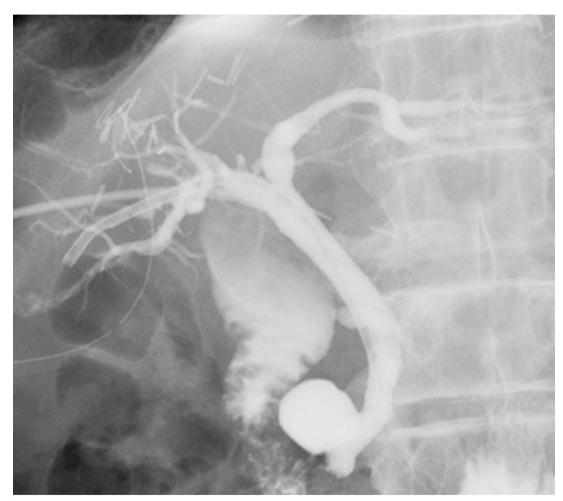

- Fig. 5 Cholangiography after endoscopic insertion of a plastic stent across the biliary disconnection showing biliary recanalization.

after laparoscopic right anterior hepatectomy. Complete obstruction at the right hepatic duct (RHD) and bile spillage at the edge of the right posterior branch (RPB) indicated complete disconnection between the RHD and RPB ( $\triangleright$ Fig.1, - Fig.2), and guidewire negotiation across the lesion failed both endoscopically and percutaneously.

Selective negotiation with an intraductal cholangioscope (SpyGlass DS; Boston Scientific, Natick, Massachusetts, USA)

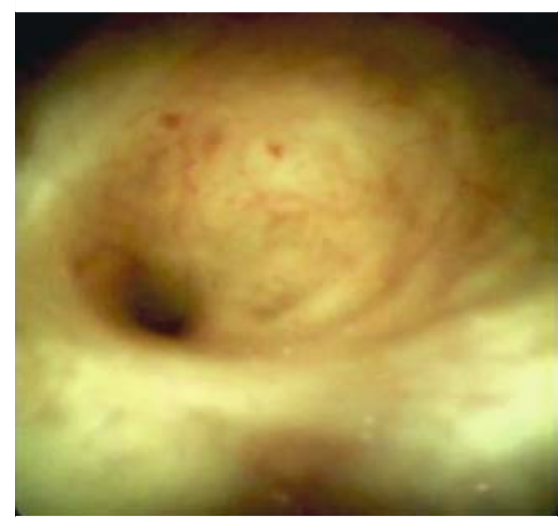

- Fig. 3 Direct cholangioscopy showing the narrow orifice of the biliary obstruction.

allowed the guidewire to reach the obstructed site of the RHD ( $\triangleright$ Fig. 3). After balloon dilation of the duct, the cholangioscope was advanced to the intraperitoneal cavity through the obstructed site. Nevertheless, the guidewire passed through the cholangioscope was unable to reach the disconnected RPB because of deep angular misalignment between the RHD and RPB. To create a fistula, a straight-type guidewire was inserted percutaneously through the disconnected RPB. The guidewire was grasped using biopsy forceps (SpyBite; Boston Scientific) under direct visualization ( $\triangleright$ Fig.4) and pulled out into the duodenum, so that the percutaneous catheter could then be advanced into the duodenum ( $\vee$ Video 1 ). Finally, a plastic stent was inserted endoscopically, followed by removal of the percutaneous catheter ( Fig.5).

Complete biliary disconnection is an intractable adverse effect of hepatectomy. Moreover, angular misalignment between the disconnected ducts is a serious obstacle for recanalization, which can mean surgical re-operation is required. Several studies have reported the utility of cholangioscopy-assisted guidewire placement in biliary obstruc- 


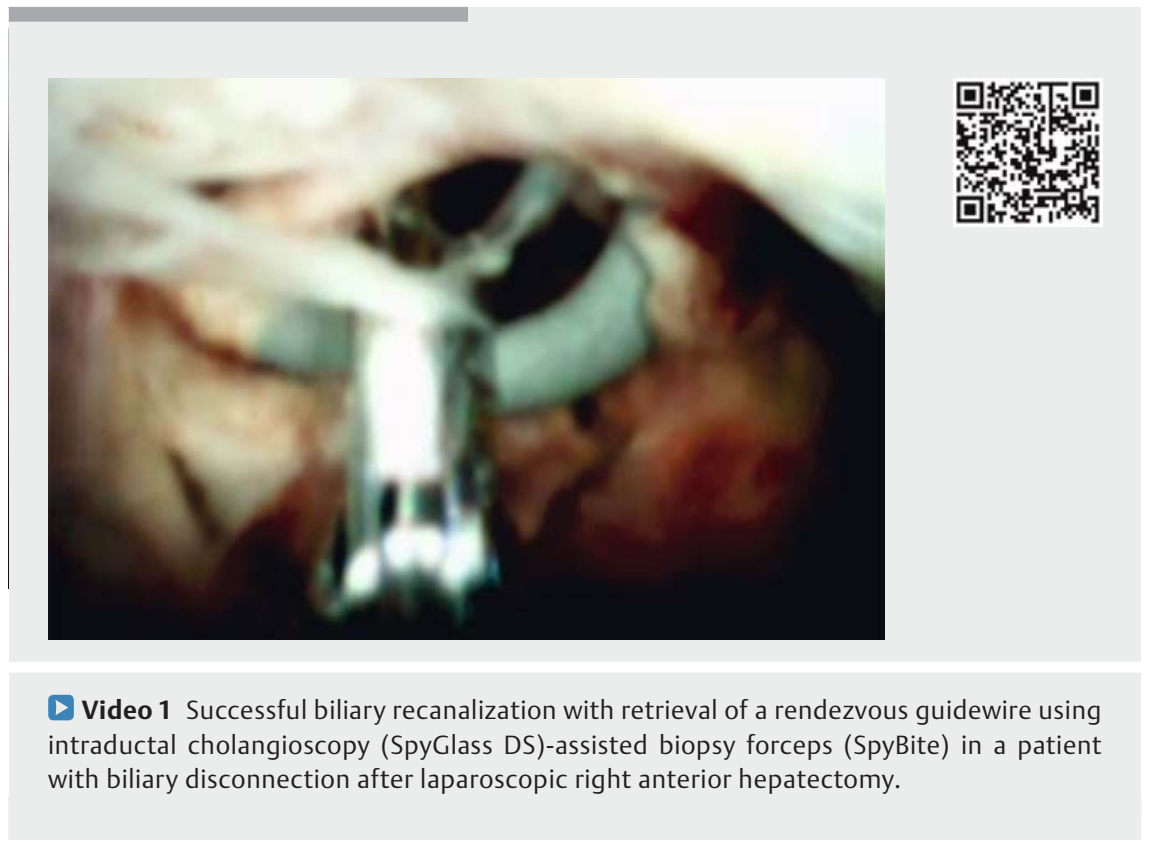

tion [1-4]. However, to the best of our knowledge, this is the first report demonstrating the combinational utility of the SpyGlass DS and SpyBite forceps for recanalization of a complete biliary disconnection with angular misalignment. The SpyGlass DS can work as a "guidewire retriever," as well as a "guidewire inserter."

Endoscopy_UCTN_Code_TTT_1AR_2A

\section{Competing interests}

None

Michihiro Yoshida ${ }^{1}$, Mamoru Morimoto ${ }^{2}$,

Akihisa Kato ${ }^{1}$, Kazuki Hayashi ${ }^{1}$, Itaru Naitoh ${ }^{1}$, Katsuyuki Miyabe' ${ }^{1}$, Yoichi Matsuo ${ }^{2}$ Metabolism, Nagoya City University Graduate School of Medical Sciences, Nagoya, Japan

2 Department of Gastroenterological Surgery, Nagoya City University Graduate School of Medical Sciences, Nagoya, Japan

\section{Corresponding author}

[1] Martins FP, Ferrari AP. Cholangioscopyassisted guidewire placement in post-liver transplant anastomotic biliary stricture: efficient and potentially also cost-effective Endoscopy 2017; 49: E283-E284

[2] Bukhari MA, Haito-Chavez Y, Ngamruengphong $S$ et al. Rendezvous biliary recanalization of complete biliary obstruction with direct peroral and percutaneous transhepatic cholangioscopy. Gastroenterology 2018; 154: $23-25$

[3] Hakuta R, Kogure H, Nakai Y et al. Successful guidewire placement across hilar malignant biliary stricture after deceased donor liver transplantation using new digital cholangioscopy. Endoscopy 2018; 50: E54-E56

[4] Kawakami H, Ban T, Kubota Y et al. Rendezvous biliary recanalization with combined percutaneous transhepatic cholangioscopy and double-balloon endoscopy. Endoscopy 2018; 50: E146-E148

\section{Bibliography}

DOI https://doi.org/10.1055/a-0667-7751

Published online: 19.9.2018

Endoscopy 2018; 50: E338-E339

(c) Georg Thieme Verlag KG

1 Department of Gastroenterology and

\author{
Kazuki Hayashi, MD \\ Department of Gastroenterology and \\ Metabolism, Nagoya City University \\ Graduate School of Medical Sciences, \\ 1 Kawasumi, Mizuho-cho, Mizuho-ku Nagoya \\ 467-8601, Japan \\ khayashi@med.nagoya-cu.ac.jp
}

\section{ENDOSCOPY E-VIDEOS}

https://eref.thieme.de/e-videos

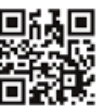
Endoscopy E-Videos is a free access online section, reporting on interesting cases and new techniques in gastroenterological endoscopy. All papers include a high quality video and all contributions are freely accessible online.

This section has its own submission website at https://mc.manuscriptcentral.com/e-videos 